\title{
Mechanical Properties Comparing Composite Fiber Length to Amalgam
}

\author{
Richard C. Petersen ${ }^{1}$ and Perng-Ru Liu ${ }^{2}$ \\ ${ }^{1}$ Departments of Biomedical Engineering, Biomaterials and Restorative Sciences, University of Alabama at Birmingham, \\ SDB 539, 1919 7th Avenue South, Birmingham, AL 35294, USA \\ ${ }^{2}$ Department of Restorative Sciences, University of Alabama at Birmingham, SDB 539, 1919 7th Avenue South, Birmingham, \\ AL 35294, USA
}

Correspondence should be addressed to Richard C. Petersen; richbme@uab.edu

Received 30 August 2015; Revised 17 January 2016; Accepted 19 January 2016

Academic Editor: Francesco Aymerich

Copyright (C) 2016 R. C. Petersen and P.-R. Liu. This is an open access article distributed under the Creative Commons Attribution License, which permits unrestricted use, distribution, and reproduction in any medium, provided the original work is properly cited.

\begin{abstract}
Photocure fiber-reinforced composites (FRCs) with varying chopped quartz-fiber lengths were incorporated into a dental photocure zirconia-silicate particulate-filled composite (PFC) for mechanical test comparisons with a popular commercial spherical-particle amalgam. FRC lengths included $0.5-\mathrm{mm}, 1.0 \mathrm{~mm}, 2.0 \mathrm{~mm}$, and $3.0 \mathrm{~mm}$ all at a constant 28.2 volume percent. Fourpoint fully articulated fixtures were used according to American Standards Test Methods with sample dimensions of $2 \times 2 \times 50 \mathrm{~mm}^{3}$ across a $40 \mathrm{~mm}$ span to provide sufficient Euler flexural bending and prevent top-load compressive shear error. Mechanical properties for flexural strength, modulus, yield strength, resilience, work of fracture, critical strain energy release, critical stress intensity factor, and strain were obtained for comparison. Fiber length subsequently correlated with increasing all mechanical properties, $p<1.1 \times 10^{-5}$. Although the modulus was significantly statistically higher for amalgam than all composites, all FRCs and even the PFC had higher values than amalgam for all other mechanical properties. Because amalgams provide increased longevity during clinical use compared to the standard PFCs, modulus would appear to be a mechanical property that might sufficiently reduce margin interlaminar shear stress and strain-related microcracking that could reduce failure rates. Also, since FRCs were tested with all mechanical properties that statistically significantly increased over the PFC, new avenues for future development could be provided toward surpassing amalgam in clinical longevity.
\end{abstract}

\section{Introduction}

Dental professionals must assume responsibility over time for providing a level of care that is expected to be no less than continuous quality improvement above historically related standards. Since the late 1960s, amalgam has experienced a decline in the United States at over 75\% of all restorations to only about $50 \%$ by 1991 [1] and an overall $78 \%$ reduction in placement from 157 million in 1977 to just 66 million in 1999 [2]. Conversely, in the United States, particulate-filled composites (PFCs) have increased use in load-bearing molars and surpassed amalgam for the number of fillings placed in the late 1990s [2]. It is known that the critical barrier for both dental composites and amalgam is primarily bacterial recurrent decay at the margins, but with lower PFC lifetimes compared to the amalgam [3-25]. On the other hand, future improvement is expected for PFCs since instruction for posterior placement was minimal in most dental schools before 1990 increasing to a level where PFCs account for about $30 \%$ of all posterior fillings in a 2005 survey [26]. In addition, improved materials and clinician experience have significantly reduced failures of the posterior $\operatorname{PFC}[26,27]$. Regarding the need for continual dental composite research and development, amalgam has further experienced several problems related to potential toxicity-related biocompatibility [28] that has resulted in several countries discouraging and even banning silver-alloy filling placement [27].

Amalgam has been mechanically tested historically by compressive stress and occasionally by tensile tests that produce results on the order of about 6-11x lower than 
compressive values [29-32]. Conversely, the more recent development of the dental PFC has been historically tested by flexural-test standards developed through the American National Standards Institute (ANSI) and International Standards Organization (ISO) [33] that should produce values very close to tensile tests ideally. In addition, photocure chopped or discontinuous fiber-reinforced composites (FRCs) have demonstrated highly significant mechanical property improvements over similar PFCs during flexural testing [34-37]. Significant statistical differences for FRC mechanical property improvements over PFC included flexural strength, modulus, yield strength, resilience, work of fracture $(\mathrm{WOF})$, critical strain energy release $\left(S_{I c}\right)$, critical stress intensity factor $\left(K_{I c}\right)$, and strain that in turn appear to be important for future development of restorative dental materials.

To better understand general advantages and disadvantages between amalgams and composites toward future material development, equivalent flexural-test results should be available for comparison. Therefore, a range of chopped quartz-fiber FRCs at different lengths, a quality zirconia-silicate PFC, and a standard commercial amalgam were extensively tested by advanced four-point flexural methods according to American Standards Test Methods (ASTM) protocol.

\section{Materials and Methods}

2.1. Samples. Quartz fibers (Saint-Gobain, QPC Products, Lexington, KY), supplied as yarn at $99.99 \%$ pure silica, were chopped to fiber lengths of $0.5,1.0,2.0$, and $3.0 \mathrm{~mm}$ and silanated with $1.0 \mathrm{wt} \%$ 3-methacryloxypropyltrimethoxysilane (MPTMS) (DOW Chemical, Midland, MI) in 70\% 2propanol, dried overnight, and heated briefly at $120^{\circ} \mathrm{C}$. The silanated discontinuous quartz fibers were then impregnated with a photocure resin at $70 \mathrm{wt} \%$ fibers. The bisphenyl A vinyl ester resin consisted of 2,2-bis [ $p$ - $\left(2^{\prime}\right.$-hydroxy- $3^{\prime}$-methacryloxypropoxyphenyl)]propane (BisGMA) resin (Esstech, PA) and was combined with $2.5 \mathrm{wt} \%$ triethylene glycol dimethacrylate (TEGDMA) monomer (Esstech, Essington, PA) to reduce viscosity. Resin systems were optimized to photocure by incorporating photooxidants camphorquinone (Aldrich, Milwaukee, WI) 0.6 wt $\%$ and Irgacure 819 (Ciba, Tarrytown, NY) $1.0 \mathrm{wt} \%$, and photoreductant 2-dimethylaminoethyl methacrylate (Aldrich, Milwaukee, WI) $1.0 \mathrm{wt} \%$. Adhesion promoter SR9016 diacrylate (Sartomer, West Chester, PA) and MPTMS organosilane were added to the photocure resin as well at 2.0 and $1.0 \mathrm{wt} \%$, respectively. Silanated chopped quartz fibers were preimpregnated using the photocure resin system. The resultant chopped quartz-fiber-reinforced compounds were then thickened with $0.3 \mathrm{wt} \%$ zirconia-silicate filler from 3 M Corporation (St. Paul, MN). The zirconia-silicate particulate had been milled into spheres by a proprietary process to provide a uniform particle distribution from $10 \mathrm{~nm}$ to $3.5 \mu \mathrm{m}$. The zirconia-silicate particulate thus provides a hydrolytically stable thickener with high atomic numbers for radiographic purposes. BisGMA vinyl ester resin and TEGDMA monomer were then combined at a 50:50 ratio in a similar photocure system for the addition of $84.5 \mathrm{wt} \%$ or 66 vol\% $3 \mathrm{M}$ Corporation zirconia-silicate particulate supplied silanated by the manufacturer. The resultant PFC provided a clean photocure system identical to a $\mathrm{Z} 100^{\circledR}$ commercial product with full free-radical activity without residual storage free-radical contaminants. The resultant paste with possible additional zirconia silicate was then used to incorporate all fiber length groups preimpregnated with photocure resin for final molding compounds with $30 \mathrm{wt} \%$ (uniform $28.2 \mathrm{~V}_{f}$ ) fibers.

Samples $2 \times 2 \times 50 \mathrm{~mm}^{3}$ meeting American National Standards Institute (ANSI)/American Dental Association (ADA) specification number 27 but for a longer span at $40 \mathrm{~mm}$ rather than $20 \mathrm{~mm}$ were prepared with a split mold clamped between two glass plates. Epilar 3000 (3 M Corporation, St. Paul, MN) was used for the photocure initiation and monitored with a Demetron Radiometer daily to ensure intensities of concentrated light at a wavelength of $470 \mathrm{~nm}$ were above $500 \mathrm{~mW} / \mathrm{cm}^{2}$. The Epilar had a $12 \mathrm{~mm}$ diameter light guide to photocure samples. Samples were irradiated by a small overlapping sequence for a total of $20 \mathrm{~s}$ on top and bottom, through the glass plates, $20 \mathrm{~s}$ on top and bottom after removing the glass plates, and from the sides for $1 \mathrm{~min}$ each with a focused $2 \mathrm{~mm}$ diameter beam. Excess material was removed from each sample followed by a sanding process down to 600-grit silicon carbide. Samples were then placed in a $37^{\circ} \mathrm{C}$ water bath for $24 \mathrm{~h}$, primarily as a control for uniform postcure before mechanical testing.

Tytin ${ }^{\circledR}$ Regular $600 \mathrm{mg}$ amalgam capsules (Kerr, Orange, CA) supplied as spherical particulate and $42.5 \%$ mercury (Hg) were triturated according to the manufacturer instructions and placed by increments in a $2 \times 2 \times 50 \mathrm{~mm}^{3}$ mold. Further, 2 operators were employed with an electricpneumatic condenser to ensure that all amalgam increments were placed under 2 minutes. In addition, samples were allowed to set for a 48-hour period before mechanical testing as the manufacturer recommended 24-hour-set period produced unacceptable highly inferior results for all properties except modulus. Conversely, modulus was actually temporally excessive during a tremendous transformation period in mechanical properties between 24-hour and 48hour amalgam set.

2.2. Flexural-Test Methods. Flexural-test methods recommended for dental materials by ANSI and ISO are not accepted ASTM flexural-test methods due to lack of pure-Euler bending. ASTM recommends a span-to-depth ratio of at least 16 to prevent compressive top-shear loading that reduces mechanical test results whereas current dental standards recommend a span-to-depth ratio of just 10 [36]. In fact, results for PFCs and FRCs with identical sample dimensions demonstrated significant improvements for flexural quarter-point mechanical properties in modulus, flexural strength, and WOF when extending $20 \mathrm{~mm}$ flexural lengths to a $40 \mathrm{~mm}$ span [36]. In the current investigation, quarter-point $20 \mathrm{~mm}$ spaced loading noses with $40 \mathrm{~mm}$ span and self-articulating fixtures were used for the mechanical testing. Four specimens from the PFC group, each FRC length group $(0.5 \mathrm{~mm}, 1.0 \mathrm{~mm}, 2.0 \mathrm{~mm}$, and $3.0 \mathrm{~mm})$, and the amalgam group were tested. An MTS inspection machine (858 MiniBionix) with a crosshead speed of 
$0.5 \mathrm{~mm} / \mathrm{minute}$ was used to mechanically test flexural properties by

$$
\begin{aligned}
& \text { Flexural Strength }(\sigma): \sigma=\frac{3 F L}{4 b d^{2}} \\
& \text { Flexural Modulus }(E): E=\frac{0.17 L^{3} M}{b d^{3}},
\end{aligned}
$$

specifying $F$ as maximum load, $L$ as span length, $b$ as sample width, $d$ as sample depth, and $M$ as slope of the tangent to the initial straight line on the steepest part of the load-deflection curve, and

$$
\text { Yield Strength (YS): YS }=\frac{3 F_{y} L}{4 b d^{2}},
$$

for $F_{y}$ where plastic deformation yielding starts as deflection increases rapidly beyond the initial steep load-deflection slope.

Resilience is measured in $\mathrm{kJ} / \mathrm{m}^{2}$ units where energy was integrated by numerical methods from the load-deflection curve up to the yield point for cross-sectional area toughness $[35,36]$.

WOF is measured in $\mathrm{kJ} / \mathrm{m}^{2}$ units where energy was integrated by numerical methods from the load-deflection curve out past maximum load until the force dropped back to no more than $5 \%$ deflection past critical load for crosssectional area toughness $[35,36]$.

$S_{I c}$ is measured in $\mathrm{kJ} / \mathrm{m}^{2}$ units where crack-propagation energy was integrated by numerical methods for area during Mode I (I) Euler-tensile flexural bending under the loaddeflection curve from peak or critical load $(c)$ until the force dropped back to no more than $5 \%$ deflection past critical load $[35,36] . S_{I c}$ toughness is then a function of energy relative to the material cross-sectional area.

$K_{I c}$ in $\mathrm{MPa} \cdot \mathrm{m}^{1 / 2}$ units can be derived by direct numerical integration methods and (1) for strength and (2) for modulus from the load-deflection curve by (4) where correction factors $(\mathrm{Y})$ are replaced by real-data-calculated values for $\sigma$ and the WOF that serve the same purpose [37] whereby

$$
\begin{aligned}
K_{I c} & =\sigma(\pi a)^{1 / 2}=\mathrm{Y}\left(E G_{I c}\right)^{1 / 2} \\
& =\mathrm{y}\left(E S_{I c}\right)^{1 / 2} \text { or }(\sigma \mathrm{WOF})^{1 / 2}+\left(E S_{I c}\right)^{1 / 2} .
\end{aligned}
$$

We further signify $a$ as the crack tip length or half the crack length and $G_{I c}$ as strain energy release rate equivalent to $S_{I c}$ described in more detail in a previous publication [37]. $\mathrm{Y}$ is replaced as $(\sigma \mathrm{WOF})^{1 / 2}$ representing the starter crack up to critical load as an additive correction factor [37]. The convenience of accurate-real-data values easily calculated from the load-deflection curve is then available without suspect $\mathrm{Y}$ correction factors greatly criticized by the United States National Academy of Sciences as not providing bulkmaterial results [38]:

$$
\text { Strain }(r): r=\frac{(4.36 * D d)}{\left(L^{2}\right)},
$$

further denoting $r$ without units at maximum strain in the outer fibers at midspan on the tensile surface at maximum load and $D$ as sample beam deflection as digitally provided at maximum bend strength by (5).

2.3. Failure Analysis. Fracture theory was developed through a correlation matrix where mechanical properties were analyzed with the vertical-crack length measured from the lowertensile-failure surface as a ratio with sample depth of the composite samples and further compared to fiber length. Imaging was done by Nikon digital micrographs for crack-depth measurements. In addition, characterization was accomplished by scanning electron micrographs (SEMs) for composites comparing amalgam Nikon micrographs for sample fracture.

2.4. Statistics. Regression analyses were done using Statistica and Microsoft Excel. $t$-tests were carried out by unequal variances with Microsoft Excel. Marginal level of uncertainty was set at $\alpha=0.05$.

\section{Results}

3.1. Mechanical Properties. Mechanical flexural-test results for the PFC, FRC at $3.0 \mathrm{~mm}$ length, and amalgam are shown in Figures 1(a)-1(h). Further, linear regression is calculated for composite mechanical properties between the PFCs at $0.0 \mathrm{~mm}$ to $0.5 \mathrm{~mm}, 1.0 \mathrm{~mm}, 2.0 \mathrm{~mm}$, and $3.0 \mathrm{~mm}$ quartz-fiber lengths. Table 1 further presents group averages and statistical differences by $p$ values between the amalgam and all fiber length groups with the PFC group for each mechanical test result.

Amalgam was tested at different set periods and flexuraltest span conditions presented in Figure 2 and Table 2.

3.2. Correlation Coefficient Fracture Analysis. A correlation matrix, Table 3, was developed with both Pearson product correlation coefficients and $p$ values to examine relationships for improvements with fiber length and many of the mechanical properties including failure analysis by the degree of fracture depth, in addition to the examined parameter interrelationships.

3.3. Imaging Analysis. SEM composite images in Figures 3(a)-3(e) show noticeable lessening in open tensile flexural fractures from the PFC that continually decrease by increasing fiber lengths from $0.0 \mathrm{~mm}$ up to $3.0 \mathrm{~mm}$. In addition, Figure 3(f) at higher SEM magnification provided examples from a crack image where possible fiber fracture, fiber pullout, and fiber bridging were occurring. Images for amalgam characterization by Nikon micrographs further demonstrate representative samples for fracture failure in Figures 3(g)3(h). The sample in Figure 3(g) was chosen as the amalgam bottom surface with the least amount of cracking.

\section{Discussion}

Fibers dominate FRC material properties evidenced by the uniform positive fiber length regressions for the experimental results in Figures $1(\mathrm{a})-1(\mathrm{~h}), p<1.1 \times 10^{-5}$, and overall 


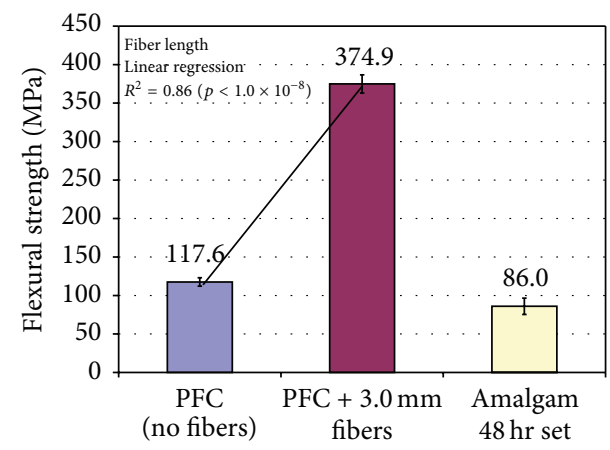

(a)

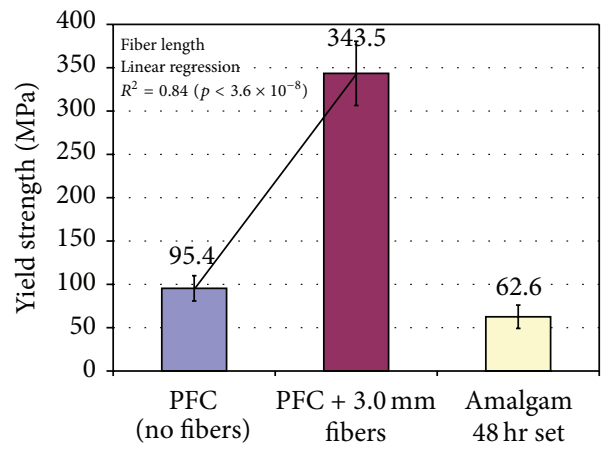

(c)

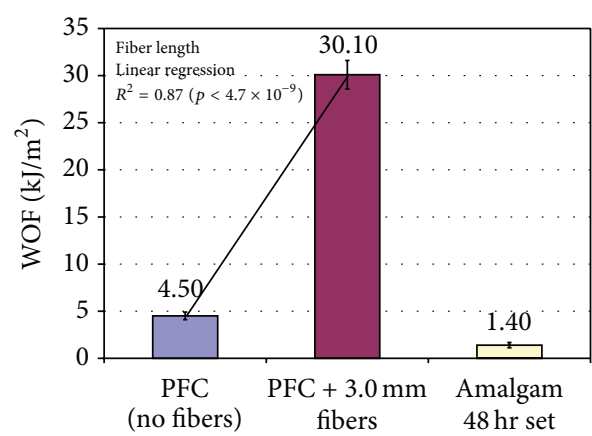

(e)

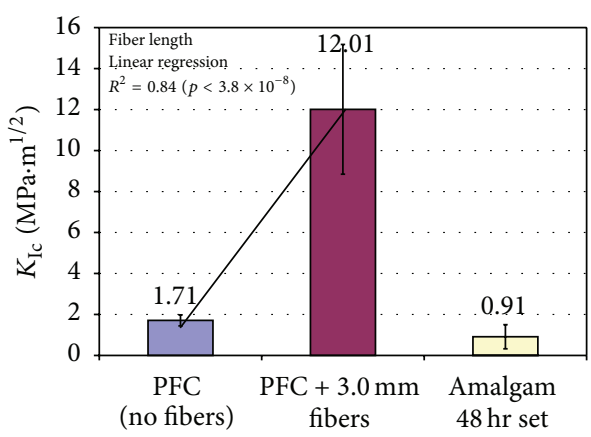

(g)

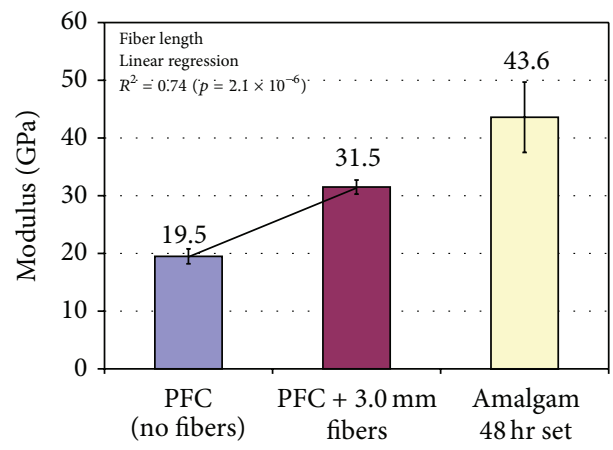

(b)

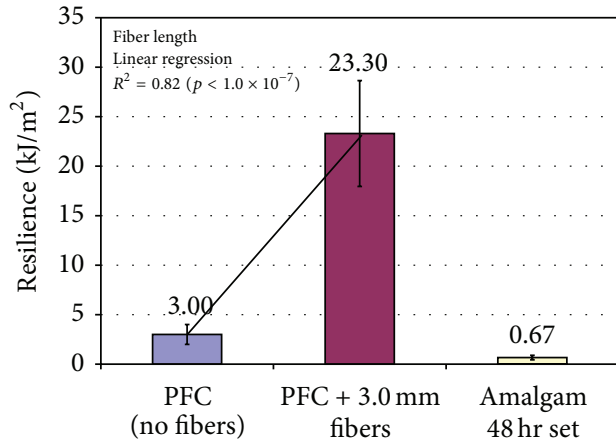

(d)

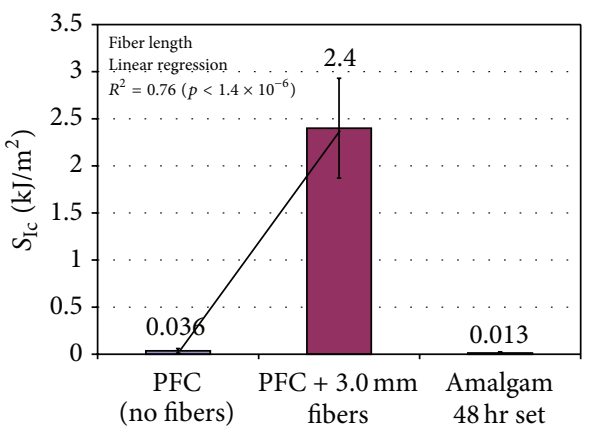

(f)

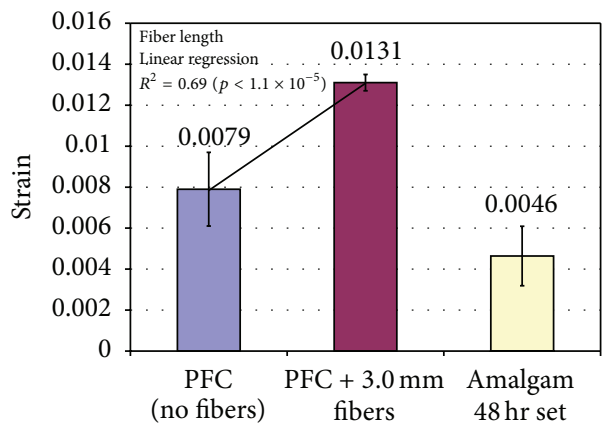

(h)

FIgURE 1: Mechanical properties for PFC, PFC with 28.2 vol\% $3.0 \mathrm{~mm}$ chopped quartz fibers, and amalgam with $48 \mathrm{hr}$ set. Regression with $R^{2}$ variability and $p$ values for chopped quartz-fiber lengths of $0.0 \mathrm{~mm}, 0.5 \mathrm{~mm}, 1.0 \mathrm{~mm}, 2.0 \mathrm{~mm}$, and $3.0 \mathrm{~mm}$. (a) Flexural strength, (b) modulus, (c) yield strength, (d) resilience, (e) work of fracture, (f) critical strain energy release, (g) critical stress intensity factor, and (h) strain at peak load. For comparisons: human dentin tensile strength $104 \mathrm{MPa}$ and modulus $13.7 \mathrm{GPa}$ [39] and $K_{I c}$ soaked in water approximately 2.5 MPa $\cdot \mathrm{m}^{1 / 2}$ [40]; human enamel modulus $48 \mathrm{GPa}$ [41] to $94 \mathrm{GPa}$ and $K_{I c} 0.77 \pm 0.05 \mathrm{MPa} \cdot \mathrm{m}^{1 / 2}$ [42]; human bone longitudinal, cortical, and tensile strength 70-150 MPa, yield strength 30-70 MPa, and modulus 15-30 GPa [43]. 
TABLE 1: Averages and $t$-test ( $p$ value) comparisons between composites and amalgam.

\begin{tabular}{|c|c|c|c|c|c|c|c|c|}
\hline $\begin{array}{l}\text { Fiber } \\
\text { length } \\
(\mathrm{mm})\end{array}$ & $\begin{array}{c}\text { Flexural } \\
\text { strength } \\
(\mathrm{MPa})\end{array}$ & $\begin{array}{l}\text { Modulus } \\
\text { (GPa) }\end{array}$ & $\begin{array}{c}\text { Yield } \\
\text { strength } \\
(\mathrm{MPa})\end{array}$ & $\begin{array}{c}\text { Resilience } \\
\left(\mathrm{kJ} / \mathrm{m}^{2}\right)\end{array}$ & $\begin{array}{c}\text { WOF } \\
\left(\mathrm{kJ} / \mathrm{m}^{2}\right)\end{array}$ & $S_{\text {Ic }}\left(\mathrm{kJ} / \mathrm{m}^{2}\right)$ & $\begin{array}{c}K_{I c} \\
\left(\mathrm{MPa} \cdot \mathrm{m}^{1 / 2}\right)\end{array}$ & $\begin{array}{l}\text { Strain at } \\
\text { peak load }\end{array}$ \\
\hline 0.0 (PFC) & $\begin{array}{c}117.6 \\
(0.0012)\end{array}$ & $\begin{array}{c}19.5 \\
(0.00102)\end{array}$ & $\begin{array}{c}95.4 \\
(0.01337)\end{array}$ & $\begin{array}{c}3.03 \\
(0.01882)\end{array}$ & $\begin{array}{c}4.48 \\
\left(5.1 \times 10^{-5}\right)\end{array}$ & $\begin{array}{c}0.036 \\
(0.16055)\end{array}$ & $\begin{array}{c}1.71 \\
(0.06584)\end{array}$ & $\begin{array}{c}0.0079 \\
(0.9740)\end{array}$ \\
\hline 0.5 & $\begin{array}{c}113.8 \\
(0.1399)\end{array}$ & $\begin{array}{c}23.0 \\
(0.0008)\end{array}$ & $\begin{array}{c}92.8 \\
(0.0372)\end{array}$ & $\begin{array}{c}2.35 \\
(0.0400)\end{array}$ & $\begin{array}{c}3.91 \\
(0.0984)\end{array}$ & $\begin{array}{c}0.075 \\
(0.1794)\end{array}$ & $\begin{array}{c}1.93 \\
(0.07953)\end{array}$ & $\begin{array}{c}0.0062 \\
(0.9189)\end{array}$ \\
\hline 1.0 & $\begin{array}{c}173.6 \\
(0.00318)\end{array}$ & $\begin{array}{c}26.2 \\
(0.001875)\end{array}$ & $\begin{array}{c}126.1 \\
(0.00018)\end{array}$ & $\begin{array}{c}3.84 \\
(0.00083)\end{array}$ & $\begin{array}{c}8.7 \\
(0.01879)\end{array}$ & $\begin{array}{c}0.097 \\
(0.0584)\end{array}$ & $\begin{array}{c}2.77 \\
(0.00797)\end{array}$ & $\begin{array}{c}0.0084 \\
(0.2993)\end{array}$ \\
\hline 2.0 & $\begin{array}{c}373.9 \\
\left(5.2 \times 10^{-5}\right)\end{array}$ & $\begin{array}{c}34.0 \\
(0.00116)\end{array}$ & $\begin{array}{c}329.8 \\
(0.00168)\end{array}$ & $\begin{array}{c}19.7 \\
(0.00287)\end{array}$ & $\begin{array}{c}28.2 \\
(0.00046)\end{array}$ & $\begin{array}{c}1.882 \\
(0.0338)\end{array}$ & $\begin{array}{c}11.01 \\
(0.00579)\end{array}$ & $\begin{array}{c}0.0121 \\
(0.1290)\end{array}$ \\
\hline 3.0 & $\begin{array}{l}374.9 \\
(2.2 \times \\
\left.10^{-8}\right)\end{array}$ & $\begin{array}{c}31.5 \\
(0.01236)\end{array}$ & $\begin{array}{c}343.5 \\
(0.00014)\end{array}$ & $\begin{array}{c}23.3 \\
(0.00348)\end{array}$ & $\begin{array}{c}30.1 \\
(4.2 \times \\
\left.10^{-5}\right)\end{array}$ & $\begin{array}{c}2.4 \\
(0.00296)\end{array}$ & $\begin{array}{c}12.01 \\
\left(3.89 \times 10^{-5}\right)\end{array}$ & $\begin{array}{c}0.0131 \\
(0.0677)\end{array}$ \\
\hline Amalgam & 86.0 & 43.6 & 62.6 & 0.67 & 1.40 & 0.013 & 0.91 & 0.0078 \\
\hline
\end{tabular}

TABLE 2: Mechanical properties for Tytin alloy at 24 hours and 48 hours (st. dev.).

\begin{tabular}{lccc}
\hline Mechanical property & 24-hour 3 pt. 20 mm span & 24-hour 4 pt. $40 \mathrm{~mm}$ span & 48-hour 4 pt. 40 mm span \\
\hline Flexural strength $(\mathrm{MPa})$ & $0.44(0.04)$ & $0.19(0.02)$ & $86.00(10.64)$ \\
Modulus $(\mathrm{GPa})$ & $272.57(107.82)$ & $197.64(55.94)$ & $43.63(6.13)$ \\
Yield strength $(\mathrm{MPa})$ & $0.44(0.04)$ & $0.19(0.02)$ & $62.56(13.50)$ \\
Resilience $\left(\mathrm{kJ} / \mathrm{m}^{2}\right)$ & $0.001(0.000)$ & $0.001(0.000)$ & $0.67(0.23)$ \\
WOF $\left(\mathrm{kJ} / \mathrm{m}^{2}\right)$ & $0.001(0.000)$ & $0.001(0.000)$ & $1.40(0.28)$ \\
$S_{I c}\left(\mathrm{~kJ} / \mathrm{m}^{2}\right)$ & $0.00015(0.00010)$ & $0.00008(0.00001)$ & $0.013(0.012)$ \\
$K_{I c}\left(\mathrm{MPa} \cdot \mathrm{m}^{1 / 2}\right)$ & $0.19(0.03)$ & $0.12(0.02)$ & $0.91(0.52)$ \\
Strain & $0.0022(0.0009)$ & $0.0021(0.0001)$ & $0.0078(0.0050)$ \\
\hline
\end{tabular}

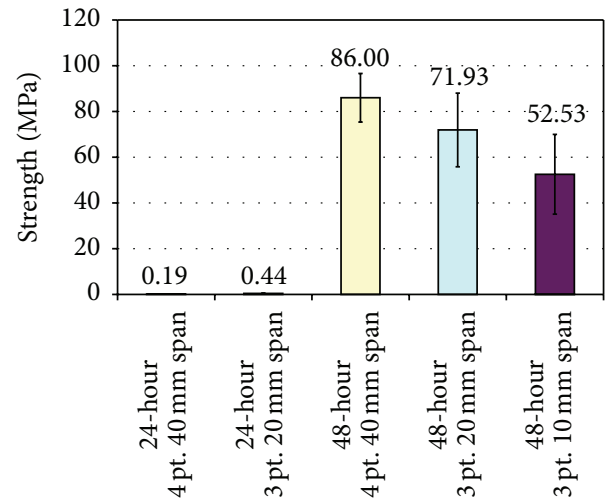

FIGURE 2: Chart for amalgam flexural-test results at 24 hours and 48 hours with both 3-point bend and 4-point bend spans at different lengths.

mechanical test correlations in Table 3 also with unusually low $p$ values. Although $0.5 \mathrm{~mm}$ fibers produced a general small decrease in many of the mechanical properties lower than the PFC, Table 1, micromechanics predict fiberrelated defects due to full debonding of fibers at the same approximate critical length [35]. All composite mechanical properties were better than amalgam except for modulus that was statistically significantly higher for amalgam than all composites. Correlation between fiber lengths and failure examined by degree-of-fracture values was extremely statistically significant, $p<2.1 \times 10^{-9}$. Regarding failure analysis, fiber length had the highest linear relationship with degreeof-fracture depth $(R=-0.940672)$, followed by WOF $(R=$ $-0.928299)$, and then flexural strength $(R=-0.924982)$ and $K_{I c}(R=-0.896627)$. In terms of validity for the current amalgam mechanical test comparisons, previous tensile tests for 16 different amalgams have produced values in a range from 42.5 to $62.1 \mathrm{MPa}$ [29-32]. In contrast, tensile failure by the existing investigation with ASTM flexural testing gave a much higher amalgam average of $86 \mathrm{MPa}$ but at the extended 48-hour set. Also, a possibility exists that amalgam mechanical properties would continue to increase over longer times. In fact, in a 1949 study, amalgam compressive or crushing strength was shown over a six-month period to slowly continually increase after the initial 6-8-hour set [30].

Tested values on modulus were higher for the amalgam $(43.6 \mathrm{GPa})$ over the composites $(19.5-34.0 \mathrm{GPa})$ and closer to approximate values for enamel (48-94 GPa) [41, 42]. Conversely FRC moduli with fiber lengths from $0.5 \mathrm{~mm}$ to $3.0 \mathrm{~mm}$ in a range from 23 to $34.0 \mathrm{GPA}$ and the PFC at $19.5 \mathrm{GPA}$ could be compared more to dentin (13.7 GPa) [39] and bone (15-30 GPa) [43]. More importantly, although 


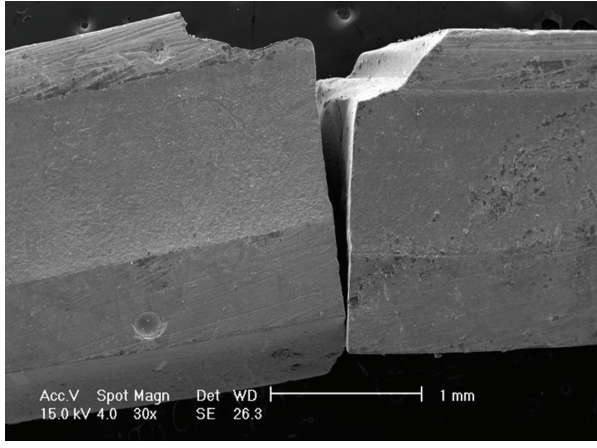

(a)

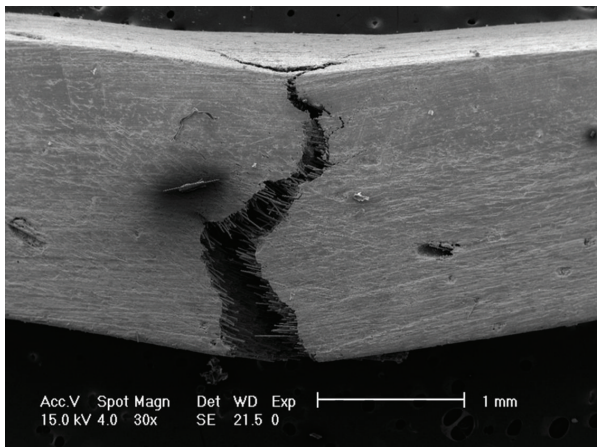

(c)
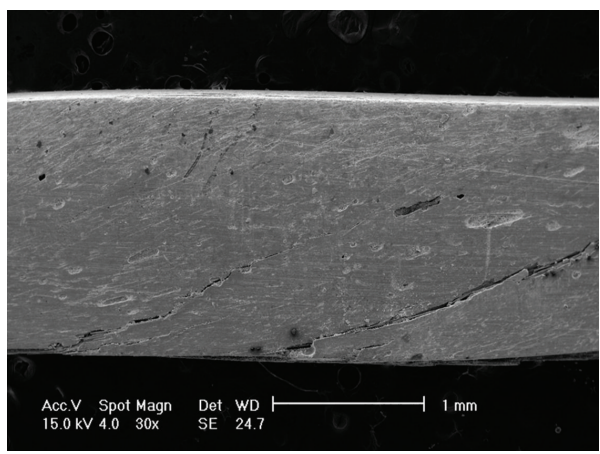

(e)

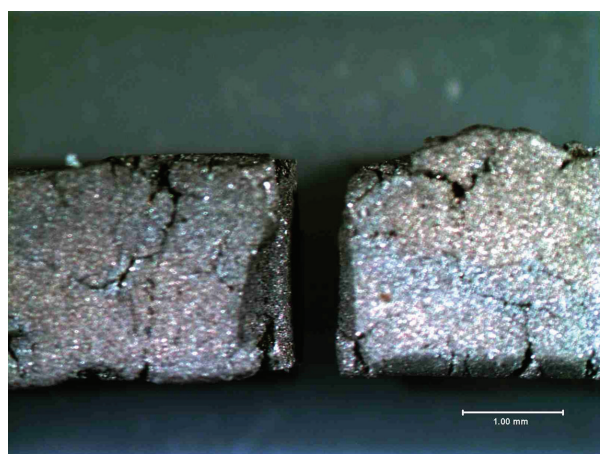

(g)

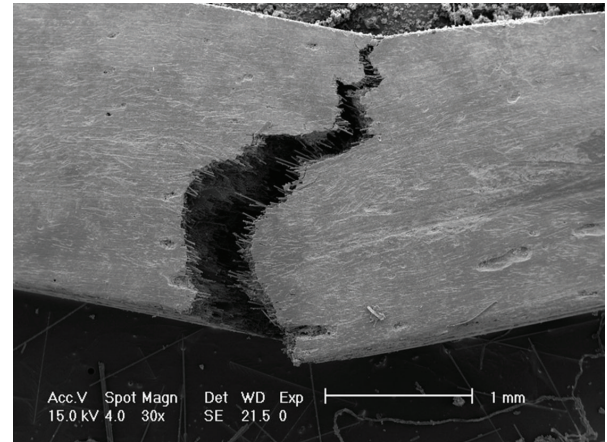

(b)

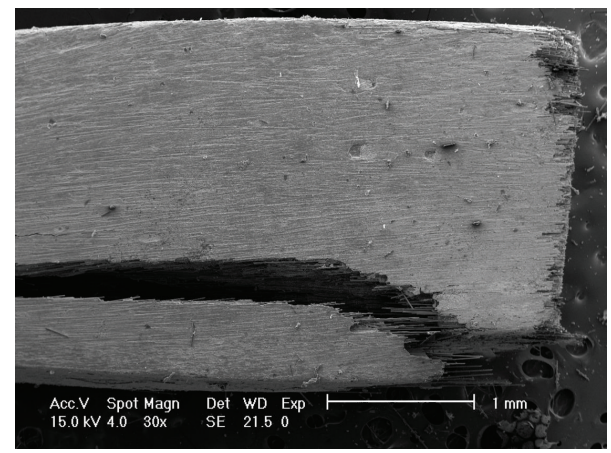

(d)

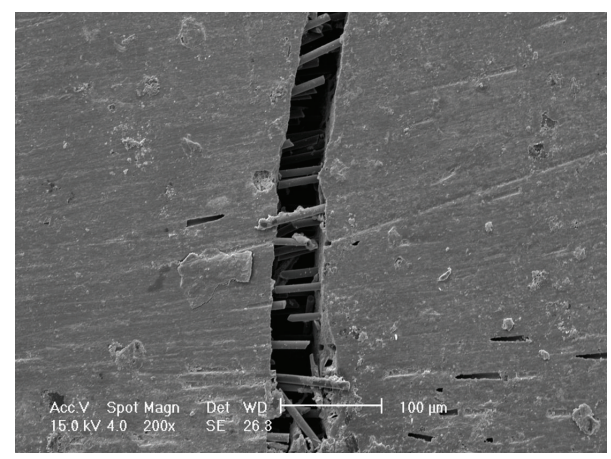

(f)

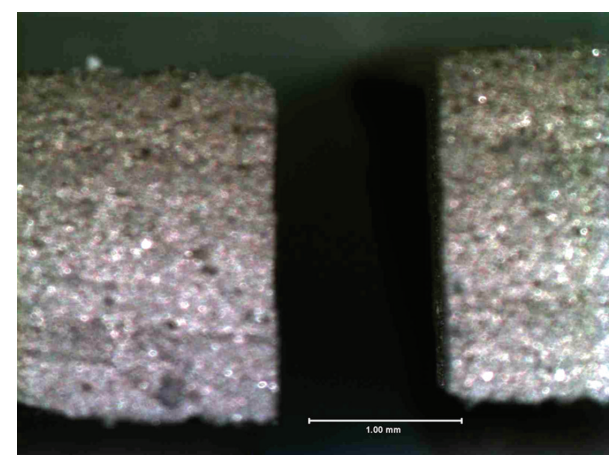

(h)

Figure 3: Flexural fracture samples: (a) SEM 30x, no fibers; (b) SEM 30x, 0.5 mm fibers; (c) SEM 30x, 1.0 mm fibers; (d) SEM 30x, 2.0 mm fibers; (e) SEM 30x, $3.0 \mathrm{~mm}$ fibers; (f) SEM 200x fiber fracture, bridging, and pullout. Scale bar: $100 \mu \mathrm{m}$. (g) Nikon micrograph amalgam bottom surface, scale bar: $1.0 \mathrm{~mm}$. (h) Nikon micrograph amalgam top surface, scale bar: $1.0 \mathrm{~mm}$. 
TABLE 3: Correlation coefficient matrix fracture analysis ( $p$ values).

\begin{tabular}{|c|c|c|c|c|c|c|c|}
\hline & Fiber length & $\begin{array}{l}\text { Flexural } \\
\text { strength }\end{array}$ & Modulus & WOF & $S_{I c}$ & $K_{I c}$ & $\begin{array}{c}\text { Degree } \\
\text { fracture } \\
\text { depth }\end{array}$ \\
\hline Length & 1.000000 & $\begin{array}{c}0.928050 \\
\left(1.0 \times 10^{-8}\right)\end{array}$ & $\begin{array}{c}0.861638 \\
\left(2.1 \times 10^{-6}\right) \\
\end{array}$ & $\begin{array}{c}0.934687 \\
\left(4.7 \times 10^{-9}\right) \\
\end{array}$ & $\begin{array}{c}0.869319 \\
\left(1.4 \times 10^{-6}\right)\end{array}$ & $\begin{array}{c}0.915848 \\
\left(3.8 \times 10^{-8}\right)\end{array}$ & $\begin{array}{l}-0.940672 \\
\left(2.1 \times 10^{-9}\right)\end{array}$ \\
\hline Strength & & 1.000000 & $\begin{array}{c}0.931744 \\
\left(6.7 \times 10^{-9}\right)\end{array}$ & $\begin{array}{c}0.996124 \\
\left(2.2 \times 10^{-19}\right)\end{array}$ & $\begin{array}{c}0.913242 \\
\left(4.9 \times 10^{-8}\right)\end{array}$ & $\begin{array}{c}0.975863 \\
\left(1.1 \times 10^{-12}\right)\end{array}$ & $\begin{array}{c}-0.924982 \\
\left(1.5 \times 10^{-8}\right)\end{array}$ \\
\hline Modulus & & & 1.000000 & $\begin{array}{c}0.908892 \\
\left(7.2 \times 10^{-8}\right) \\
\end{array}$ & $\begin{array}{c}0.810965 \\
\left(2.5 \times 10^{-5}\right) \\
\end{array}$ & $\begin{array}{c}0.893058 \\
\left(2.7 \times 10^{-7}\right)\end{array}$ & $\begin{array}{l}-0.830431 \\
\left(1.1 \times 10^{-5}\right)\end{array}$ \\
\hline WOF & & & & 1.000000 & $\begin{array}{c}0.933409 \\
\left(5.5 \times 10^{-9}\right)\end{array}$ & $\begin{array}{c}0.984717 \\
\left(2.4 \times 10^{-14}\right)\end{array}$ & $\begin{array}{l}-0.928299 \\
\left(1.0 \times 10^{-8}\right)\end{array}$ \\
\hline$S_{I c}$ & & & & & 1.000000 & $\begin{array}{c}0.977671 \\
\left(5.9 \times 10^{-13}\right)\end{array}$ & $\begin{array}{l}-0.844474 \\
\left(5.4 \times 10^{-6}\right)\end{array}$ \\
\hline$K_{I c}$ & & & & & & 1.000000 & $\begin{array}{l}-0.896627 \\
\left(2.0 \times 10^{-7}\right) \\
\end{array}$ \\
\hline Fracture & & & & & & & 1.000000 \\
\hline
\end{tabular}

both PFC and FRC mechanical properties were superior to amalgams for strength and toughness, the reverse clinicallongevity association between PFCs and amalgam [3-25] then might possibly suggest other alternate composite failure mechanisms related to the mechanical property for modulus or approximately stiffness. As an example, PFC material with a lower modulus would resist strain less than amalgam metal and deform through interlaminar shear stress more into the cavity as another factor related to breaking the marginal cavity bond with the higher modulus tooth enamel. In addition, lower modulus PFC would strain more to initiate polymer matrix microcracking. In fact, applied stress accelerates moisture uptake by opening up polymer voids and initiating microcracks that will adsorb more water [44]. As the PFC filling distorts under a load by shearing against the tooth wall and opens the cavity margin with adhesive bond breaking, microcracking would be most detrimental at the enamel and filling marginal interface. Subsequent margin defects could then lead to even more moisture ingress with bacterial infiltration further leading to bigger failure rates with secondary decay. On the other hand, from test results, moduli for the FRCs can significantly statistically increase over the dental PFC with increasing fiber lengths to reduce problems related to interlaminar shear stress deformation of the filling material at the bond interface with the cavity tooth margin and also strain-related microcracking.

In terms of general adhesive bonding to joints, polymer matrix adherends are more sensitive to interlaminar shear stress and tensile stresses than metals [45]. Again, masticatory loading onto the cavity margin would produce interlaminar shear stress deflections more pronounced in a dental PFC with lower modulus than a stiff metal alloy filling material. In effect, the lower modulus polymer adherend material will deflect by interlaminar shear stress to a much greater extent under masticatory loading than a stiffer metal alloy amalgam to more easily break and open up the marginal cavity bond. As a countermeasure for polymer matrix materials, bond deflections are limited by the presence of high-modulus fibers
[45]. Further, polymer matrix adherends are susceptible to moisture that is not the case with metals where moisture is found on the adhesive layer but is confined mostly to exposed edges on the metal [45]. As a result, chopped fibers in mat carriers for adhesives are commonly used to prevent moisture ingress into the bond [45]. Also, with microcracking dimensional instability increases moisture adsorption rates and levels of moisture [44, 45]. Although moisture adsorption increases with polarity of the polymer chain molecules, diffusion is the chief mechanism for moisture ingress where water molecules enter the polymer and reside in positions between polymer chains that become forced apart [29]. As water enters the polymer, the chains become less entangled and more mobile so that the polymer plasticizes or softens and also hydrolyzes [29, 44-46] with loss of composite mechanical properties [45] such as strength and modulus [44, 46]. Resin hydrophilicity as tendency for a polymer to adsorb moisture has been shown to reduce polymer strength after water storage [47]. Also, dental PFCs have shown significant reductions in strength when stored in water [48]. Possible strain-related microcracking from lower modulus dental PFC materials would then appear to accelerate such moisture ingress not only at the adhesive joint but also within the entire PFC. The fact that dental PFCs are not recommended by the American Dental Association in stress bearing areas [49] may be due to loss of mechanical strength particularly over time from water adsorption. Further, deeper, larger fillings with more surfaces are identified as reasons for using amalgam instead of composite [20, 50, 51]. In addition, as filling sizes increase, cavity margins have a greater possibility of encountering stresses that would more easily deform a lower modulus PFC to break the adhesive bond. So, although mechanical properties with strength and fracture toughness for PFCs are better than amalgam in an air environment, over time, in an oral moisture environment, loss of mechanical properties with more applied loading stress at the margins could be the reason why PFCs are considered unsuitable for larger posterior fillings. 
Concerning another major marginal interface problem, polymer matrix composites shrink during polymerization curing that produces residual stresses along the stationary surface walls $[29,52]$. One of the most characteristic features for free-radical covalent bonding from a resin to solid polymer structure with increased modulus and density properties becomes most apparent in materials that polymerize by covalent chain-growth polymerization as the linear/volumetric cure shrinkage $[29,45,52-56]$. In fact, free radicals are engineered for specific and accurate polymerization application to cross-link molecules with subsequent cure shrinkage and possibly warpage as two of the most distinguished material problems of extensive polymer electron-pair covalent bonding [56]. Because polymerization shrinkage is not necessarily perfect with inhomogeneous material, nonuniform electronpairing during curing in addition to increasing the modulus or stiffness can also create residual internal stresses to produce warpage of materials which weakens parts $[45,56]$. Subsequent residual cure stresses from polymerization cure shrinkage into the bulk of the material are then prone to opening up a defect at the margins of dental PFCs [29, 52]. In fact, polymerization cure shrinkage is considered a major clinical problem with dental PFCs that can produce bacterial sensitivity [57]. On the other hand, with incremental curing, FRCs shrink during the polymerization cure process by stabilizing the polymer matrix with the high-modulus fibers in a planar fashion onto the floor of the cavity and a wall or margin with reduced shrinkage along the fiber axis [58]. Further, $9 \mu \mathrm{m}$ diameter fibers in a polymer matrix molding compound will consolidate by pressure along a cavity wall during packing insertion to squeeze unwanted lower molecular weight monomers, excess resin, and particle filler toward the cavity surface and away from the margins sealing the margin interface with an elevated concentration of high-modulus fiber material that is insoluble $[34,58]$. Atomic Force Microscopy (AFM) that provides better visual images of FRC molding paste compressed by a flat instrument from another study illustrates the top surface layer of PFC pressed up to the surface when compared to the same sample but with a chip exposing an underlying chopped quartz-fiber yarn, Figure 4. Another AFM image shows how a $9 \mu \mathrm{m}$ diameter individual quartz fiber will mold by bending $90^{\circ}$ without full breakage and PFC paste that fills all space around the fiber during consolidation, Figure 5. Figures 4 and 5 were obtained with permission from Dr. Petersen [59, Figures 1-3].

As a tacky paste without a viable consolidation process, the dental PFC presents another major serious concern for voids when developing a filling material that more successfully competes with amalgams in clinical longevity [58]. On the other hand, FRCs increase viscosities as discontinuous fibers are added [60]. Consequently, common dental PFC voids [58, 61-66], Figure 6 , can be practically eliminated by FRCs that mold with consolidating properties [58, 61]. Problems with voids have been sufficiently notable that the American Dental Association Council of Dental Materials at the November 1980 meeting suggested specifications be set for X-ray density radiopacification in class II restorations that describes cavities with loss of a tooth lateral wall which included the requirement to detect "major voids" [62].

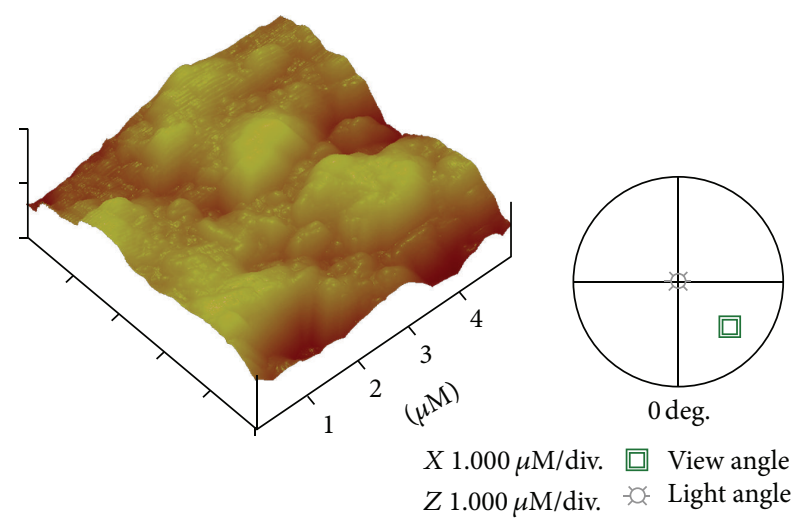

(a)

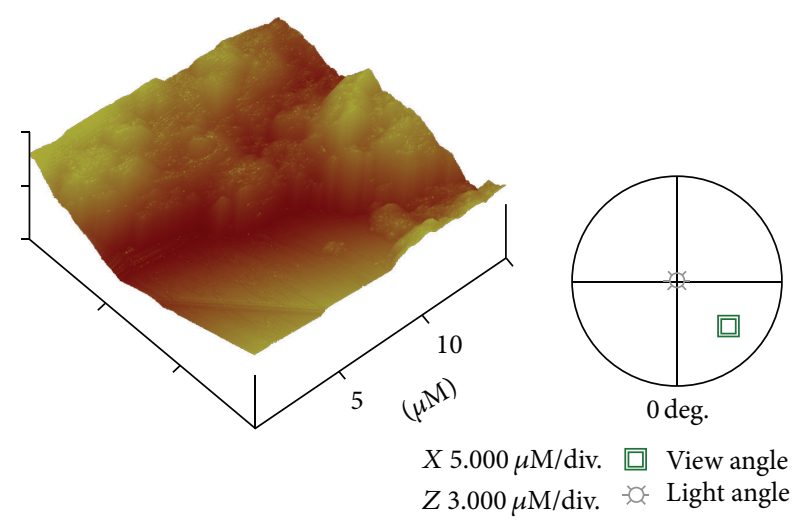

(b)

FIGURE 4: AFM surface plots of PFC material. (a) Portion of sample covered only by polymer and particulate with aspect ratios. (b) Portion of sample with chip defect exposing underlying chopped quartz yarn.

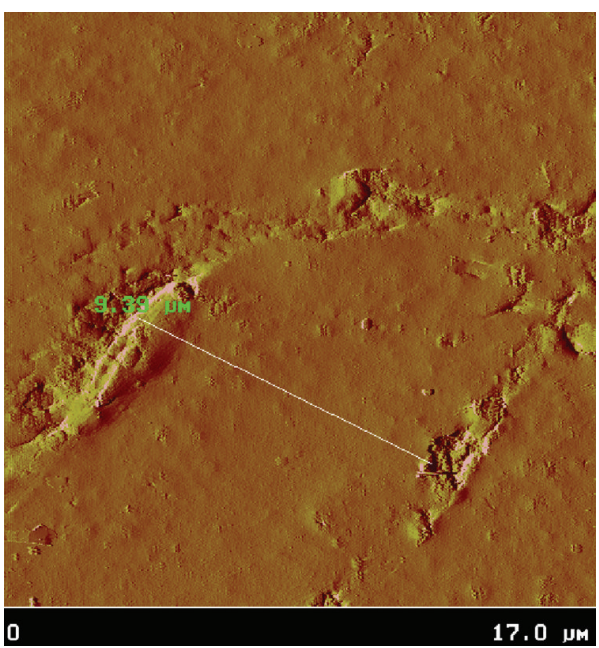

FIGURE 5: AFM 2D laser scan of $9.0 \mu \mathrm{m}$ diameter quartz fiber bent without full breakage at about 90-degree angle. Molding pressure squeezed particulate and resin toward the surface covering all fibers in the composite before photocuring. Measurement length: $9.39 \mu \mathrm{m}$. 


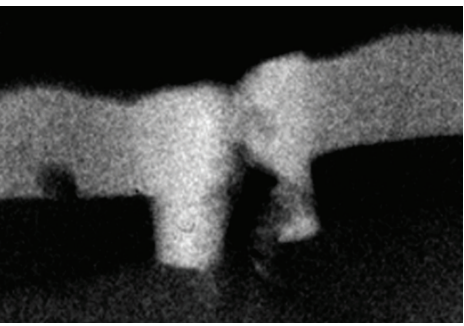

(a)

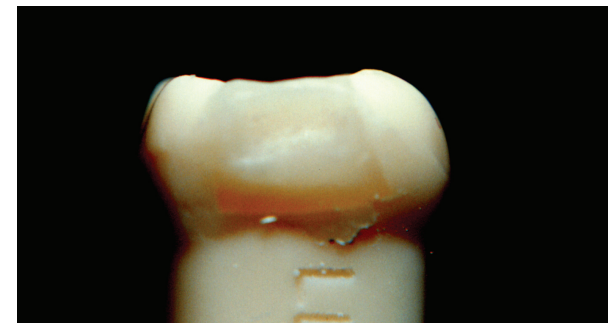

(b)

FIGURE 6: X-ray showing occlusal and class II PFC voids from a typodont mock-clinical study [77] (a) and class II photocured PFC gingival overhang (b).

Composite voids are most often left unnoticed until an X-ray or radiograph is carried out much later. Subsequent marginal moisture leakage in voids predisposes the filling to common bacterial ingress with pain often experienced [57]. Also, dental students were found to produce class II failures 10x greater for composites than with amalgams with voids charted from $\mathrm{X}$-rays as one of the common reasons for replacement at no cost [63]. Voids generally incorporate into the dentin hybrid layer as porosities at the gingival/adhesive interface as a possible reason for secondary decay acid-based deterioration adhesive error and loss of bond strength [64]. Further, voids in a class II cavity were found to be detrimental clinically for adhesive bond strength [65]. Common class II gingival overhang $[14,67,68]$, Figure 6 , also occurs due to difficultto-control runny excess PFC that flows under the matrix band as another source for bacterial collection after cure-set hardening. By controllable thickened viscosity, FRCs can be incrementally placed carefully by wedge sealing and explorer cleaned before photocuring to prevent such runny flow overhangs that may not be seen by $\mathrm{X}$-ray with radiolucent and lower-viscosity photocure bonding agent. Also, without proper consistency, dental PFCs cannot condense or pack similar to the amalgam that often prevents reestablishment of the interproximal contact in a class II filling [58, 61]. In fact, the past two most commonly mentioned clinical complaints regarding class II composites have been frequent poor interproximal contacts [69-76] and void defects in the proximal box [69].

Wear concepts for "sheltering" are based on the fact that wear for dental PFCs increases with wider cavity preparations as the enamel margins shelter the dental composite [78]. The sheltering concept was then extended successfully with micro and hybrid composites and finally heavily filled nanocomposites where smaller particles fit closer together to protect the polymer matrix to wear less than composites with larger filler diameters in the low micrometer range $[78,79]$. Without agglomeration theoretically only about $1.5-6$ vol\% filler at about $40 \mathrm{~nm}$ diameter is needed for interparticle distances of $100 \mathrm{~nm}$ that provide adequate polymer protection, but with agglomeration around $35 \mathrm{vol} \% 40 \mathrm{~nm}$ diameter filler is needed [78]. Also, larger higher modulus particles shear from applied pressure during wear into the lowermodulus polymer matrix and with polymer microcracking debond from the polymer and increase wear at a greater rate without smaller particle protection $[78,80]$. Conversely, wear improves for FRCs in conjunction with underlying mechanical strength properties that support loading, particularly as the reinforcement length extends beyond the average plowing groove [81, 82]. Further, fibers cannot debond by shearing into the soft polymer but peel off in worn thin sheets [82] and wear slowly as exceptionally strong materials for a smooth surface [58]. Also, fibers above critical lengths with a dental PFC matrix have been shown to wear even better than enamel [58].

Another practical FRC advantage over amalgam includes bonding with tooth structure. Composite bonding allows a more conservative cavity preparation with less tooth weakening than amalgam that further requires bulk for strength $[26,83]$. In addition, thermoset polymer interfaces have been extensively studied for cost-effective repair, bonding, and structural joining to avoid complete replacement [84]. In fact, composite bonded repair is instructed by over half of all United States dental schools to reduce iatrogenic undermining sound tooth structure [85]. Further again, FRCs have shown the ability to pack better than amalgam in restoring the interproximal contact, consolidate well to eliminate voids common with PFCs, and can provide pressure infiltration of resin for enhanced adhesive bonding [58, 61, 66]. Current standard dental adhesives require acid etching to provide enamel microporosity and open the dentinal tubules for micromechanical interlocking and with a subsequent rinse to remove the acid [86]. Alternatively, newer types of cement include the acid in the primer without rinse to provide a more wettable or hydrophilic and polar surface to help infiltrate dentinal tubules with resin adhesive [86]. But, adhesives that etch and rinse provide more long-lasting bonds than most adhesives that incorporate an acid [87]. Further, adhesive bond tests that etch and rinse have shown nanofillers dissolve in a water rich zone in the adhesive layer so that experts believe removing water from the resin-dentin interface is further crucial to bonding [88]. Since water diffusion into an adhesive with soluble release of unpolymerized monomer is associated with polymer softening and hydrolytic damage [89], nonpolar or hydrophobic methods that reduce the amounts of acid in the bond appear to be beneficial. Glass ionomer cement similarly has residual acids to interact 
well for adhesion to moist substrates [90]. However, when comparing marginal integrity of glass ionomers to resinbased cement after thermocycling at $5^{\circ} \mathrm{C}, 37^{\circ} \mathrm{C}$, and $55^{\circ} \mathrm{C}$ for 250 cycles and immersion in artificial saliva for 15 days, glass ionomer cement demonstrated highly significant inferior bonds with greater marginal gaps than conventional resin cement [91]. In efforts to correct bond problems, polymer matrix FRC molding compounds have thickened consistency for effective placement so that pressure can be applied [58] during adhesive bonding after complete acid elimination and water removal by solvent/air drying to apply force and push resin into the tooth deep for micromechanical interlocking. Along the margins monomer, resin and particulate are squeezed away from the surface to seal the bond with a higher concentration of insoluble high-strength pure quartz fibers $[34,58]$. Further, $9.0 \mu \mathrm{m}$ diameter yarn fibers planarize to applied forces and surfaces and bend into tight corners for easy-to-finish margins $[34,58]$.

Amalgam has one more clinical problem overlooked since premeasured capsules were developed. Fracturing on the lower flexural tensile side of the relatively larger amalgam sample, Figure 3(g), combined with reduced 24-hour-set flexural mechanical test results for amalgams that further required a 48-hour-set period may possibly be related. Although spherical particulate improves bonding compared to particulate with an aspect ratio [92], poor adaptability between the initial increment and subsequent increments during the packing phase of spherical particulate Tytin amalgam is considered. According to earlier recommendations to improve amalgam plasticity and adaptability, $\mathrm{Hg}$ was historically removed lightly with a squeeze cloth in the first increment for large fillings and then progressively squeezed out harder with each successive increment [93]. However, with the premeasured capsules, all $\mathrm{Hg}$ content is the same. In fact, during the historical clinical development of amalgam, $\mathrm{Hg}$ content practically controls plasticity and adaptability of the amalgam in a relatively narrow range between 48 and $62 \%$ [94] while strength can be inversely influenced by residual $\mathrm{Hg}$ in the set amalgam [31]. By comparison, Tytin Regular amalgam mix used in the current study is supplied in premeasured capsules with a low $42.5 \% \mathrm{Hg}$ content for reduced plasticity that might dry on the bottom during the set of larger incremental placements. Although $\mathrm{Hg}$ toxicity has been well documented [28], on a positive note during the same period of premeasured capsule commercial development, $\mathrm{Hg}$ blood levels of dental professionals have declined dramatically $[95,96]$. As an explanation for reduced $\mathrm{Hg}$ blood levels, squeeze cloth handling was found to be the most common source of exposure $[1,96]$.

\section{Conclusions}

FRCs are the original engineering design material and should vastly improve dental composites during future development. Research strategy includes protecting composites from bacterial colonization by stabilizing surfaces and interfaces from all manners of defects with increasing mechanical properties. As fiber lengths and volume percentages increase, FRCs greatly increase all mechanical properties significantly over common dental PFCs and even over the amalgam filling for all properties except modulus. Subsequent lower PFC modulus appears to play a role in reduced longevity compared to the amalgam that better resists interlaminar shear stress deformation and strain-related microcracking at the highly susceptible cavity margin with the tooth that could open the bond interface. Photocure FRC molding compounds can also pack into a cavity better than the amalgam alloy for easy clinician operator success more easily satisfied to further help overcome multiple serious problems experienced with the dental PFC.

\section{Conflict of Interests}

The authors declare that there is no conflict of interests regarding the publication of this paper.

\section{Acknowledgments}

This project was supported in part by funding through the National Institutes of Health Grant no. T32DE014300. SEMs were provided by Dr. Vladimir M. Dusevich, Director of Electron Microscopy Laboratory, University of MissouriKansas City. AFMs were provided by the laboratory of Dr. Yip-Wah Chung, Director of Materials Science, School of Engineering, Northwestern University.

\section{References}

[1] ADA Council on Scientific Affairs, "Dental amalgam: update on safety concerns," The Journal of the American Dental Association, vol. 129, no. 4, pp. 494-503, 1998.

[2] Council on Scientific Affairs, "Direct and indirect restorative materials," Journal of the American Dental Association, vol. 134, no. 4, pp. 463-472, 2003.

[3] P. Spencer, Q. Ye, J. Park et al., "Adhesive/dentin interface: the weak link in the composite restoration," Annals of Biomedical Engineering, vol. 38, no. 6, pp. 1989-2003, 2010.

[4] K. K. Skjörland, "Plaque accumulation on different dental filling materials," Scandinavian Journal of Dental Research, vol. 81, no. 7, pp. 538-542, 1973.

[5] K. K. Skjorland, "Bacterial accumulation on silicate and composite materials," Journal de Biologie Buccale, vol. 4, no. 4, pp. 315-322, 1976.

[6] D. Ørstavik and A. Pettersen, "Bacterial activity of toothcolored dental restorative materials," Journal of Dental Research, vol. 57, pp. 141-174, 1978.

[7] K. K. R. Skjørland and T. Sönju, "Effect of sucrose rinses on bacterial colonization on amalgam and composite," Acta Odontologica Scandinavica, vol. 40, no. 4, pp. 193-196, 1982.

[8] M. Svanberg, I. A. Mjör, and D. Ørstavik, "Mutans streptococci in plaque from margins of amalgam, composite, and glassionomer restorations," Journal of Dental Research, vol. 69, no. 3, pp. 861-864, 1990.

[9] C. G. Matasa, "Microbial attack of orthodontic adhesives," American Journal of Orthodontics and Dentofacial Orthopedics, vol. 108, no. 2, pp. 132-141, 1995.

[10] C. Hansel, G. Leyhausen, U. E. H. Mai, and W. Geurtsen, "Effects of various resin composite (co)monomers and extracts on two caries-associated micro-organisms in vitro," Journal of Dental Research, vol. 77, no. 1, pp. 60-67, 1998. 
[11] A. Karanika-Kouma, P. Dionysopoulos, E. Koliniotou-Koubia, and A. Kolokotronis, "Antibacterial properties of dentin bonding systems, polyacid-modified composite resins and composite resins," Journal of Oral Rehabilitation, vol. 28, no. 2, pp. 157-160, 2001.

[12] C. Boeckh, E. Schumacher, A. Podbielski, and B. Haller, "Antibacterial activity of restorative Dental Biomaterials in vitro," Caries Research, vol. 36, no. 2, pp. 101-107, 2002.

[13] S. Imazato, "Antibacterial properties of resin composites and dentin bonding systems," Dental Materials, vol. 19, no. 6, pp. 449-457, 2003.

[14] L. Levin, M. Coval, and S. B. Geiger, "Cross-sectional radiographic survey of amalgam and resin-based composite posterior restorations," Quintessence International, vol. 38, no. 6, pp. 511-514, 2007.

[15] J. A. Soncini, N. N. Maserejian, F. Trachtenberg, M. Tavares, and C. Hayes, "The longevity of amalgam versus compomer/composite restorations in posterior primary and permanent teeth findings from the New England children's Amalgam trial," The Journal of the American Dental Association, vol. 138, no. 6, pp. 763-772, 2007.

[16] A. Gama-Teixeira, M. R. L. Simionato, S. N. Elian, M. A. P. Sobral, and M. A. A. D. C. Luz, "Streptococcus mutans-induced secondary caries adjacent to glass ionomer cement, composite resin and amalgam restorations in vitro," Brazilian Oral Research, vol. 21, no. 4, pp. 368-374, 2007.

[17] N. Beyth, A. J. Domb, and E. I. Weiss, "An in vitro quantitative antibacterial analysis of amalgam and composite resins," Journal of Dentistry, vol. 35, no. 3, pp. 201-206, 2007.

[18] M. Bernardo, H. Luis, M. D. Martin et al., "Survival and reasons for failure of amalgam versus composite posterior restorations placed in a randomized clinical trial," Journal of the American Dental Association, vol. 138, no. 6, pp. 775-783, 2007.

[19] P. Spencer, Q. Ye, J. Park et al., "Durable bonds at the adhesive dentin interface: an impossible mission or simply a moving target?” Brazilian Dental Science, vol. 15, no. 1, pp. 4-18, 2012.

[20] B. S. Bohaty, Q. Ye, A. Misra, F. Sene, and P. Spencer, "Posterior composite restoration update: focus on factors influencing form and function," Clinical, Cosmetic and Investigational Dentistry, vol. 5, pp. 33-42, 2013.

[21] C. J. Collins, R. W. Bryant, and K.-L. V. Hodge, "A clinical evaluation of posterior composite resin restorations: 8-year findings," Journal of Dentistry, vol. 26, no. 4, pp. 311-317, 1998.

[22] A. Shenoy, "Is it the end of the road for dental amalgam? A critical review," Journal of Conservative Dentistry, vol. 11, no. 3, pp. 99-107, 2008.

[23] K. Antony, D. Genser, C. Hiebinger, and F. Widisch, "Longevity of dental amalgam in comparison to composite materials," GMS Health Technology Assessment, vol. 4, Article ID Doc12, 2008.

[24] M. G. Rasines Alcaraz, A. Veitz-Keenan, P. Sahrmann, P. R. Schmidlin, D. Davis, and Z. Iheozor-Ejiofor, "Direct composite resin fillings versus amalgam fillings for permanent or adult posterior teeth," Cochrane Database of Systematic Reviews, no. 3, Article ID CD005620, 2014.

[25] M. G. Rasines Alcaraz, A. Veitz-Keenan, P. Sahrmann, P. R. Schmidlin, D. Davis, and Z. Iheozor-Ejiofor, "Amalgam or composite fillings-which materials lasts longer?" Cochran Database System Review, vol. 7, no. 3, Article ID CD005620, 2014.

[26] C. D. Lynch, R. J. McConnell, and N. H. F. Wilson, "Trends in the placement of posterior composites in dental schools," Journal of Dental Education, vol. 71, no. 3, pp. 430-434, 2007.
[27] G. J. Christensen, "Longevity vs. esthetics in restorative dentistry," Journal of the American Dental Association, vol. 129, no. 7, pp. 1023-1024, 1998.

[28] M. F. Ziff, "Documented clinical side-effects to dental amalgam," Advances in Dental Research, vol. 6, pp. 131-134, 1992.

[29] K. J. Anusavice, Dental Materials, Elsevier Saunders, St. Louis, Mo, USA, 11th edition, 2003.

[30] R. W. Phillips, "Compressive strength of amalgam as related to time," Journal of Dental Research, vol. 28, no. 4, pp. 348-355, 1949.

[31] M. L. Swartz and R. W. Phillips, "Residual mercury content of amalgam restorations and its influence on compressive strength," Journal of Dental Research, vol. 35, no. 3, pp. 458-466, 1956.

[32] E. J. Sutow, D. W. Jones, G. C. Hall, and E. L. Milne, "The response of dental amalgam to dynamic loading," Journal of Dental Research, vol. 64, no. 1, pp. 62-66, 1985.

[33] I. A. Mjör, "Problems and benefits associated with restorative materials: side-effects and long-term cost," Advances in Dental Research, vol. 6, no. 1, pp. 7-16, 1992.

[34] R. C. Petersen, "Discontinuous fiber-reinforced composites above critical length," Journal of Dental Research, vol. 84, no. 4, pp. 365-370, 2003.

[35] R. C. Petersen, J. E. Lemons, and M. S. McCracken, "Fiber length micromechanics for fiber-reinforced composites with a photocure vinyl ester resin," Polymer Composites, vol. 27, no. 2, pp. 153-169, 2006.

[36] R. C. Petersen, J. E. Lemons, and M. S. McCracken, "Fracture toughness micromechanics by energy methods with a photocure fiber-reinforced composites," Polymer Composites, vol. 28, no. 3, pp. 311-324, 2007.

[37] R. C. Petersen, "Accurate critical stress intensity factor Griffith crack theory measurements by numerical techniques," in Proceedings of the SAMPE, pp. 737-752, Society for Advanced Materials and Process Engineering, Long Beach, Calif, USA, May 2013, http://www.ncbi.nlm.nih.gov/pmc/articles/PMC4302413/.

[38] National Materials Advisory Board, "Materials characterization," in Reliability of Ceramics for Heat Engine Applications, NMAB 357,44, chapter 4, National Academy of Sciences, Washington, DC, USA, 1980.

[39] H. Sano, B. Ciucchi, W. G. Matthews, and D. H. Pashley, "Tensile properties of mineralized and demineralized human and bovine dentin," Journal of Dental Research, vol. 73, no. 6, pp. 1205-1211, 1994.

[40] R. K. Nalla, J. H. Kinney, A. P. Tomsia, and R. O. Ritchie, "Role of alcohol in the fracture resistance of teeth," Journal of Dental Research, vol. 85, no. 11, pp. 1022-1026, 2006.

[41] J. B. Parks and R. S. Lakes, Biomaterials, Plenum Press, New York, NY, USA, 2nd edition, 1992.

[42] L. Yin, X. F. Song, Y. L. Song, T. Huang, and J. Li, "An overview of in vitro abrasive finishing \& CAD/CAM of bioceramics in restorative dentistry," International Journal of Machine Tools and Manufacture, vol. 46, no. 9, pp. 1013-1026, 2006.

[43] D. R. Ratner, A. S. Hoffman, F. J. Shoen, and J. E. Lemons, Biomaterials Science, Elsevier, Boston, Mass, USA, 2nd edition, 2004.

[44] P. Robinson, E. Greenhalgh, and S. Pinho, Failure Mechanisms in Polymer Matrix Composites, WP Woodhead Publishing, Oxford, UK, 2012.

[45] S. T. Peters, Handbook of Composites, Chapman \& Hall, London, UK, 1998. 
[46] K. K. Chawla, Composite Materials, Springer, New York, NY, USA, 2nd edition, 1998.

[47] C. K. Y. Yiu, N. M. King, D. H. Pashley et al., "Effect of resin hydrophilicity and water storage on resin strength," Biomaterials, vol. 25, no. 26, pp. 5789-5796, 2004.

[48] K.-J. M. Söderholm and M. J. Roberts, "Influence of water exposure on the tensile strength of composites," Journal of Dental Research, vol. 69, no. 12, pp. 1812-1816, 1990.

[49] American Dental Association and Council on Scientific Affairs, "Statement on posterior resin-based composites," Journal of the American Dental Association, vol. 129, pp. 1627-1628, 1998.

[50] S. K. Makhija, V. V. Gordan, G. H. Gilbert et al., "Practitioner, patient and carious lesion characteristics associated with type of restorative material: findings from the dental practice-based research network," Journal of the American Dental Association, vol. 142, no. 6, pp. 622-632, 2011.

[51] J. L. Ferracane, "Current trends in dental composites," Critical Reviews in Oral Biology and Medicine, vol. 6, no. 4, pp. 302-318, 1995.

[52] C. L. Davidson and A. J. Feilzer, "Polymerization shrinkage and polymerization shrinkage stress in polymer-based restoratives," Journal of Dentistry, vol. 25, no. 6, pp. 435-440, 1997.

[53] X. A. J. Peacock and A. Calhoun, Polymer Chemistry Properties and Applications, Hanser Publishers, Munich, Germany, 2006.

[54] I. Mironi-Harpaz, M. Narkis, and A. Siegmann, "Peroxide crosslinking of a styrene-free unsaturated polyester," Journal of Applied Polymer Science, vol. 105, no. 2, pp. 885-892, 2007.

[55] Y. Wang, L. Woodworth, and B. Han, "Simultaneous measurement of effective chemical shrinkage and modulus evolutions during polymerization," Experimental Mechanics, vol. 51, no. 7, pp. 1155-1169, 2011.

[56] K. M. B. Jansen, J. de Vreugd, and L. J. Ernst, "Analytical estimate for curing-induced stress and warpage in coating layers," Journal of Applied Polymer Science, vol. 126, no. 5, pp. 1623-1630, 2012.

[57] G. Bergenholtz, "Evidence for bacterial causation of adverse pulpal responses in resin-based dental restorations," Critical Reviews in Oral Biology and Medicine, vol. 11, no. 4, pp. 467-480, 2000.

[58] R. C. Petersen, Micromechanics/Electron Interactions for Advanced Biomedical Research, LAP LAMBERT Academic Publishing, Saarbrücken, Germany, 2011.

[59] Petersen, "Atomic Force Microscopy (AFM) surface roughness evaluation of discontinuous fiber-reinforced composites," in Micromechanics/Electron Interactions for Advanced Biomedical Research, Figures 1-3, pp. 179-187, Lambert Academic Publishing (LAP), Saarbrücken, Germany, 2011.

[60] B. R. Pipes, J. W. S. Hearle, A. J. Beaussart, A. M. Sastry, and R. K. Okine, "A constitutive relation for the viscous flow of an oriented fiber assembly," Journal of Composite Materials, vol. 25, pp. 1204-1217, 1991.

[61] R. C. Petersen, "United States Patent approved chopped fiber reinforced dental material (high purity quartz) assigned United States application number 09259317 March 1, 1999," Patent number 6270348, August 2001, http://www.uspto.gov/.

[62] Council on Dental Materials-Instruments and Equipment, "The desirability of using radiopaque plastics in dentistry: a status report," The Journal of the American Dental Association, vol. 102, no. 3, pp. 347-349, 1981.
[63] J. D. Overton and D. J. Sullivan, "Early failure of class II resin composite versus class II amalgam restorations placed by dental students," Journal of Dental Education, vol. 76, no. 3, pp. 338340, 2012.

[64] A. P. Martini, R. B. Anchieta, E. P. Rocha et al., "Influence of voids in the hybrid layer based on self-etching adhesive systems: a 3-D FE analysis," Journal of Applied Oral Science, vol. 17, pp. 19-26, 2009.

[65] J. H. Purk, V. M. Dusevich, A. Glaros, and J. D. Eick, "Adhesive analysis of voids in class II composite resin restorations at the axial and gingival cavity walls restored under in vivo versus in vitro conditions," Dental Materials, vol. 23, no. 7, pp. 871-877, 2007.

[66] R. C. Petersen and E. G. Wenski, "Mechanical testing of a photocured chopped fiber-reinforced dental," in Proceedings of the 47th International SAMPE Symposium and Exhibition, pp. 380-394, Long Beach, Calif, USA, May 2002.

[67] A. Fabianelli, A. Sgarr, C. Goracci, A. Cantoro, S. Pollington, and M. Ferrari, "Microleakage in class II restorations: open vs closed centripetal build-up technique," Operative Dentistry, vol. 35, no. 3, pp. 308-313, 2010.

[68] B. A. C. Loomans, N. J. M. Opdam, F. J. M. Roeters, E. M. Bronkhorst, and M. C. D. N. J. M. Huysmans, "Restoration techniques and marginal overhang in Class II composite resin restorations," Journal of Dentistry, vol. 37, no. 9, pp. 712-717, 2009.

[69] G. J. Christiansen, "Overcoming challenges with resin in class II situations," Journal of the American Dental Association, vol. 128, no. 11, pp. 1579-1580, 1997.

[70] J. F. Roulet, "The problems associated with substituting composite resins for amalgam: a status report on posterior composites," Journal of Dentistry, vol. 16, no. 3, pp. 101-113, 1988.

[71] J. Cunningham, L. H. Mair, M. A. Foster, and R. S. Ireland, "Clinical evaluation of three posterior composite and two amalgam restorative materials: 3-year results," British Dental Journal, vol. 169, no. 10, pp. 319-323, 1990.

[72] J. F. Roulet and M. J. Noack, "Criteria for substituting amalgam with composite resins," International Dental Journal, vol. 41, no. 4, pp. 195-205, 1991.

[73] R. Wilkie, A. Lidums, and R. Smales, "Class II glass ionomer cermet tunnel, resin sandwich and amalgam restorations over 2 years," American Journal of Dentistry, vol. 6, no. 4, pp. 181-184, 1993.

[74] K. F. Leinfelder, "Posterior composite resins: the materials and their clinical performance," The Journal of the American Dental Association, vol. 126, no. 5, pp. 663-667, 1995.

[75] G. J. Kaplowitz, "Achieving tight contacts in class II direct resin restorations," The Journal of the American Dental Association, vol. 128, no. 7, pp. 1012-1013, 1997.

[76] S.-F. Chuang, K.-C. Su, C.-H. Wang, and C.-H. Chang, "Morphological analysis of proximal contacts in class II direct restorations with 3D image reconstruction," Journal of Dentistry, vol. 39, no. 6, pp. 448-456, 2011.

[77] R. C. Petersen, "Interproximal contact measurement with high viscosity experimental condensable dental composites," in Proceedings of the 77th General Session of the International/American Association for Dental Research, p. 68, Vancouver, Canada, March 1999.

[78] S. C. Bayne, D. F. Taylor, and H. O. Heymann, "Protection hypothesis for composite wear," Dental Materials, vol. 8, no. 5, pp. 305-309, 1992. 
[79] S. Schultz, M. Rosentritt, M. Behr, and G. Handel, "Mechanical properties and three-body wear of dental restoratives and their comparative flowable materials," Quintessence International, vol. 42, no. 1, pp. el-e10, 2010.

[80] K. F. Leinfelder, "Composites: current status and future developments," in Proceedings of the International State-of-the-Art Conference on Restorative Dental Materials, pp. 393-408, National Institute of Dental Research, Bethesda, Md, USA, September 1986.

[81] J. P. Giltrow, "Friction and wear of self-lubricating composite materials," Composites, vol. 4, no. 2, pp. 55-64, 1973.

[82] "Wear models for multiphase materials and synergistic effects in polymeric hybrid composites," in Advances in Composite Tribology, K. Friedrich, Ed., pp. 209-269, Elsevier, Amsterdam, The Netherlands, 1993.

[83] K. F. Leinfelder, "A conservative approach to placing posterior composite resin restorations," The Journal of the American Dental Association, vol. 127, no. 6, pp. 743-748, 1996.

[84] J. Raghavan and R. P. Wool, "Interfaces in repair, recycling, joining and manufacturing of polymers and polymer composites," Journal of Applied Polymer Science, vol. 71, no. 5, pp. 775-785, 1999.

[85] V. V. Gordan, I. A. Mjör, I. R. Blum, and N. Wilson, "Teaching students the repair of resin-based composite restorations," The Journal of the American Dental Association, vol. 134, no. 3, pp. 317-339, 2003.

[86] K. J. Anusavice, "Bonding," in Science of Dental Materials, pp. 381-398, Saunders, St. Louis, Mo, USA, 11th edition, 2003.

[87] D. H. Pashley, F. R. Tay, L. Breschi et al., "State of the art etchand-rinse adhesives," Dental Materials, vol. 27, no. 1, pp. 1-16, 2011.

[88] M. G. Brackett, N. Li, W. W. Brackett et al., "The critical barrier to progress in dentine bonding with the etch-and-rinse technique," Journal of Dentistry, vol. 39, no. 3, pp. 238-248, 2011.

[89] R. Parthasarathy, A. Misra, J. Park, Q. Ye, and P. Spencer, "Diffusion coefficients of water and leachables in methacrylate-based crosslinked polymers using absorption experiments," Journal of Materials Science: Materials in Medicine, vol. 23, no. 5, pp. 1157$1172,2012$.

[90] U. Lohbauer, "Dental glass ionomer cements as permanent filling materials?-Properties, limitations and future trends," Materials, vol. 3, no. 1, pp. 76-96, 2010.

[91] S. Gunjal, L. Nagesh, and H. G. Raju, "Comparative evaluation of marginal integrity of glass ionomer and resin based fissure sealants using invasive and non-invasive techniques: an in vitro study," Indian Journal of Dental Research, vol. 23, no. 3, pp. 320325, 2012.

[92] R. Davis and J. D. Overton, "Efficacy of bonded and nonbonded amalgam in the treatment of teeth with incomplete fractures," Journal of the American Dental Association, vol. 131, no. 4, pp. 469-478, 2000.

[93] M. L. Swartz and R. W. Phillips, "A study of amalgam condensation procedures with emphasis on the residual mercury content of the increments," Journal of Dental Research, vol. 33, no. 1, pp. 12-19, 1954.

[94] J. F. Simon Jr. and D. A. Welk, "Influence of mercury-to-alloy ratios on line angle adaptation of dental amalgam," Journal of Dental Research, vol. 49, no. 5, pp. 1055-1059, 1970.

[95] C. Naleway, H. N. Chou, T. Muller, J. Dabney, D. Roxe, and F. Siddiqui, "On-site screening for urinary Hg concentrations and correlation with glomerular and renal tubular function," Journal of Public Health Dentistry, vol. 51, no. 1, pp. 12-17, 1991.
[96] D. Echeverria, N. J. Heyer, M. D. Martin, C. A. Naleway, J. S. Woods, and A. C. Bittner Jr., "Behavioral effects of low-level exposure to $\mathrm{Hg}^{\circ}$ among dentists," Neurotoxicology and Teratology, vol. 17, no. 2, pp. 161-168, 1995. 

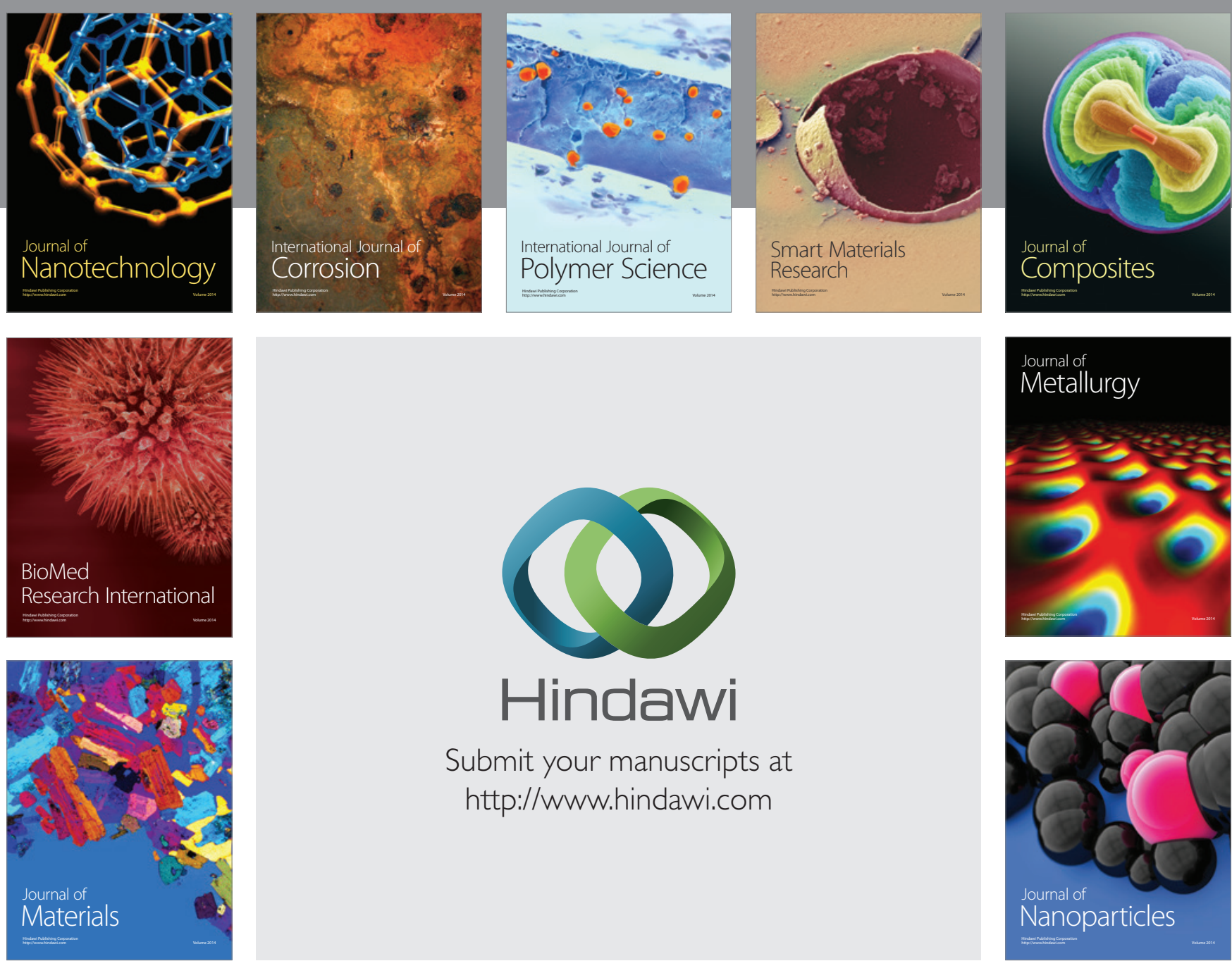

\section{Hindawi}

Submit your manuscripts at

http://www.hindawi.com

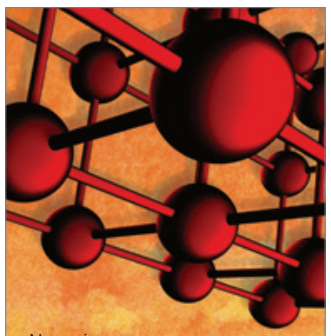

Materials Science and Engineering
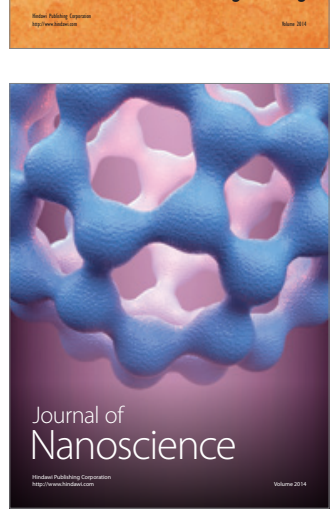
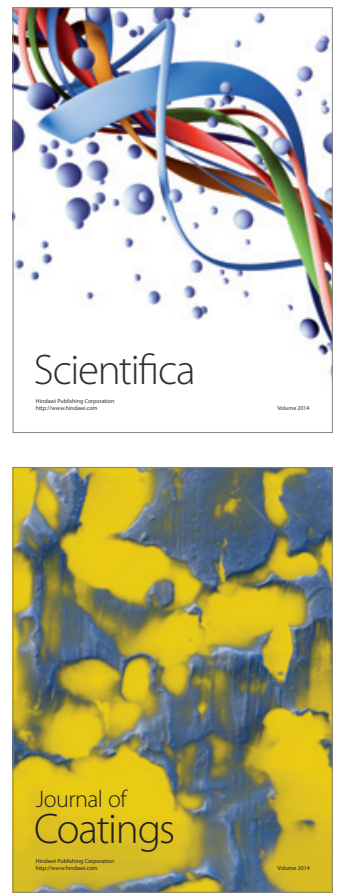
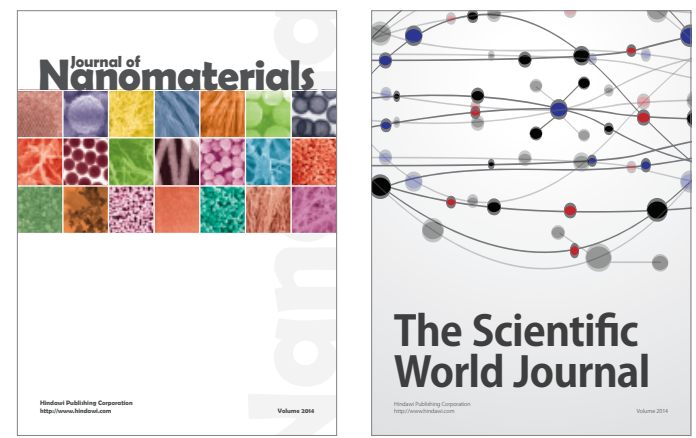

The Scientific World Journal
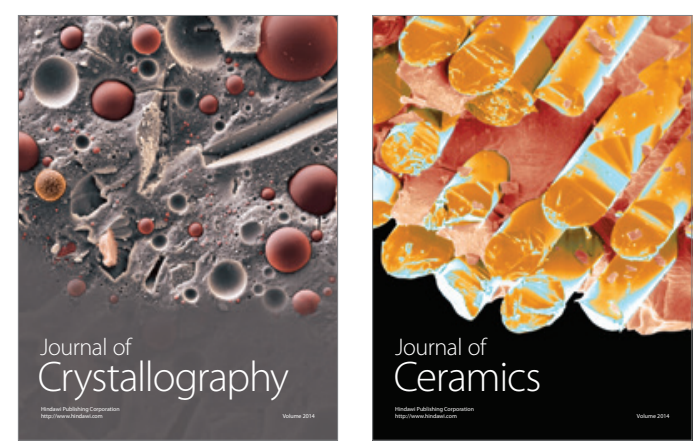
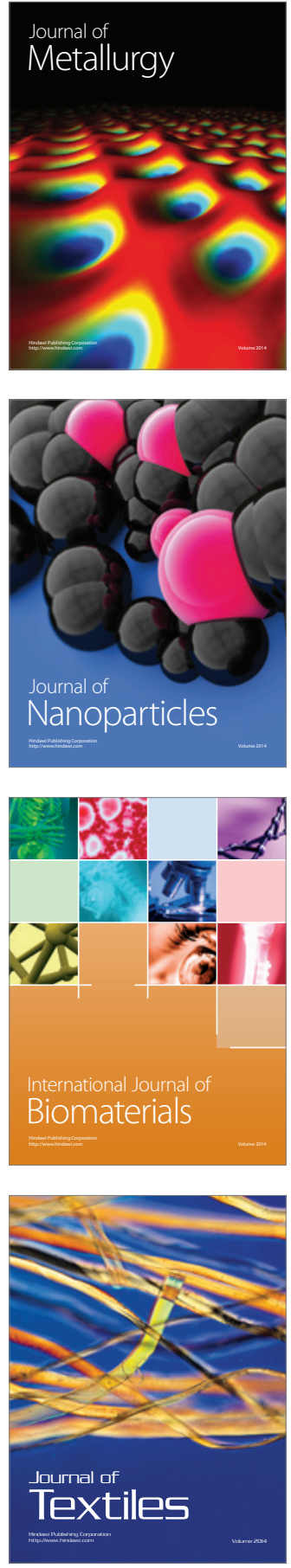